\title{
8
}
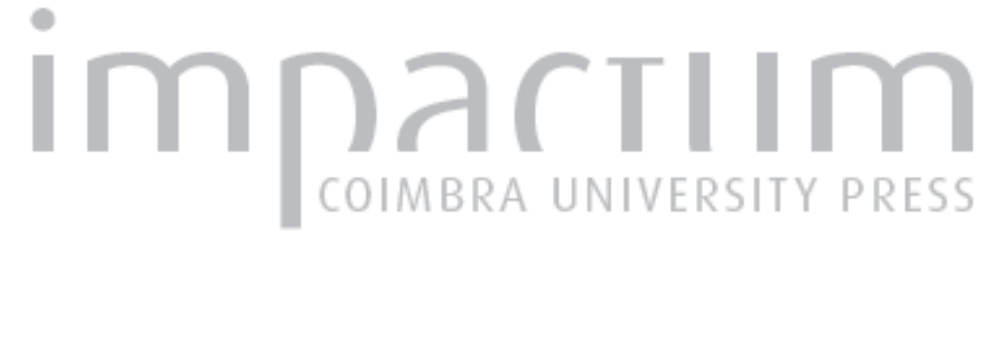

\section{Trabalhos recentes sobre riscos e catástrofes}

\section{Autor(es): Rebelo, Fernando}

Publicado por: Associação Portuguesa de Riscos, Prevenção e Segurança

URL persistente:

URI:http://hdl.handle.net/10316.2/40092

DOI:

DOI:https://doi.org/10.14195/1647-7723_9_10

Accessed : $\quad$ 26-Apr-2023 13:51:20

A navegação consulta e descarregamento dos títulos inseridos nas Bibliotecas Digitais UC Digitalis, UC Pombalina e UC Impactum, pressupõem a aceitação plena e sem reservas dos Termos e Condições de Uso destas Bibliotecas Digitais, disponíveis em https://digitalis.uc.pt/pt-pt/termos.

Conforme exposto nos referidos Termos e Condições de Uso, o descarregamento de títulos de acesso restrito requer uma licença válida de autorização devendo o utilizador aceder ao(s) documento(s) a partir de um endereço de IP da instituição detentora da supramencionada licença.

Ao utilizador é apenas permitido o descarregamento para uso pessoal, pelo que o emprego do(s) título(s) descarregado(s) para outro fim, designadamente comercial, carece de autorização do respetivo autor ou editor da obra.

Na medida em que todas as obras da UC Digitalis se encontram protegidas pelo Código do Direito de Autor e Direitos Conexos e demais legislação aplicável, toda a cópia, parcial ou total, deste documento, nos casos em que é legalmente admitida, deverá conter ou fazer-se acompanhar por este aviso.

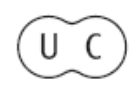




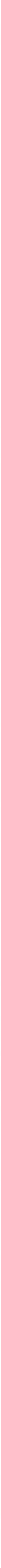




\section{NOTAS, NOTÍCIAS E RECENSÕES}

\section{Trabalhos recentes sobre riscos e catástrofes}

\section{Fernando Rebelo}

\section{Risques et Catastrophes. Observer-Spatialiser} - Comprendre-Géreréum livrode AndréDAUPHINÉ, professor da Universidade de Nice Sophia-Antipolis, publicado pela Armand Colin (Paris, 2001).

Nas suas 288 páginas encontramos as quatro partes anunciadas no subtítulo, antecedidas de uma introdução e seguidas de uma conclusão, mas também um conjunto de anexos em que se destaca uma longa e diversificada bibliografia.

No respeitante à introdução, saliente-se o facto de o Autor recordar o facto de as Nações Unidas terem lançado em 1990 um "decénio internacional" visando "reduzir os impactos das catástrofes naturais" e de afirmar desde logo que o seu livro "tem por objectivo contribuir para este vasto programa das Nações Unidas, propondo algumas reflexões de síntese a partir de monografias sempre mais numerosas" (p. 5). De notar, também, que, através de um pequeno parágrafo intitulado "a contribuição dos geógrafos para a compreensão da complexidade das catástrofes" (p. 7), esta introdução deixa claro que estamos perante um trabalho que considera a geografia "como uma ciência de síntese que analisa as relações entre a sociedade e a natureza" e o geógrafo como "o especialista da organização dos territórios". Climatólogo, A. DAUPHINÉ cita C.-P. PÉGUY, a propósito do "factor espacial", no caso dos ciclones, apresenta o exemplo das inundações de Nîmes ( 3 de Outubro de 1988) e destaca a importância dos Sistemas de Informação Geográfica (SIG). É uma introdução curta (apenas cinco páginas), mas rica em termos de ligação entre geografia e riscos naturais.

A primeira parte, "Observar", quase metade do livro, começa com um capítulo sobre terminologia. É a distinção entre risco (potencial) e catástrofe (real), entre "aléa" e vulnerabilidade, masé, igualmente a rejeição de "hasard" porque, segundo o Autor, começa por ser sinónimo de risco e passa a ser sinónimo de "aléa", quando não mesmo de perigo; além disso, "tem uma conotação emocional não negligenciável"e "está efectivamente muito próximo da fatalidade". Todavia, a definição mais aprofundada é a de catástrofe.

Outros pontos importantes tratados nesta primeira parte são os de carácter histórico no que respeita às catástrofes, bem como tudo o que consta dos capítulos sobre riscos e catástrofes de origem técnica, de origem natural, de origem social e política e de origem biológica ("riscos e catástrofes do ser vivo").
Particularmente interessante é o parágrafo dedicado ao homem como factor das catástrofes de origem natural (p. 73).

O último capítulo da primeira parte, "A complexidade funcional dos riscos e das catástrofes", é uma espécie de conclusão parcelar onde, entre outras coisas, se propõe uma classificação multicritério dos tipos de catástrofes.

A segunda parte, "Espacializar", fala da passagem "duma geografia zonal a uma geografia civilizacional das catástrofes", mas também desce ao pormenor tratando de riscos e catástrofes litorais e de montanha, tal como de riscos e catástrofes urbanos. "A complexidade territorial dos riscos e das catástrofes" é o último capítulo.

A terceira parte, "Compreender", divide-se por dois capítulos apenas - compreensão sectorial e disciplinar e compreensão global dos riscos e das catástrofes.

A quarta parte, "Gerir", fala do antes, do durante e do depois das catástrofes. Um capítulo trata de previsão, de vigilância e de alerta. Outro, da redução do risco. Outro ainda, da gestão das catástrofes. O último capítulo, naturalmente, refere-se à avaliação, à indemnização e à reconstrução. Mais do que nas outras partes do trabalho, há em toda esta quarta parte uma aproximação grande às ideias de L. FAUGERES (1990), que aceitámos e desenvolvemos para o caso dos incêndios florestais (F. REBELO, 1995).

A conclusão final é muito curta (três páginas). Refere-se ao conhecimento desigual da temática dos riscos e das catástrofes e apresenta algumas "propostas de acção".

Um pouco por todo o livro há exemplos concretos de catástrofes, com grande incidência para as que aconteceram ou acontecem ainda hoje em França. Alguns aparecem incluídos no texto principal, outros são colocados à parte como elementos de "dossier".

2. O número de Outubro de 2001 da Documentation Photographique (La Documentation Française, Paris) é da responsabilidade da professora da Universidade de Paris X, Yvette VEYRET-MEKDJIAN e intitula-se Géographie des Risques Naturels. Tem apenas 64 páginas, muito bem ilustradas por figuras e fotografias de enorme qualidade, onde um texto simples informa e faz reflectir.

A introdução intitula-se "Risques naturels et aménagements", tem 16 páginas e culmina com uma 
curta, mas actualizada bibliografia onde já consta 0 acima referido livro de A. DAUPHINÉ (2001). Logo na primeira página fica bem clarificado que, para Y. VEYRET, "risco" não se confunde com "aléa". " $O$ 'aléa' designa um processo físico ligadoà dinâmica terrestre" e "a 'vulnerabilidade' difere segundo o modo de relação que cada uma das sociedades mantém com o seu ambiente e segundo as práticas de gestão do risco que autorizam a sua organização e o seu nível de desenvolvimento". A conclusão é inevitável - " a geografia dos riscos não se sobrepõe à dos 'aléas"”.

Percepção e representação do risco natural, tipologia dos riscos naturais, catástrofes naturais e domínio dos riscos são os outros pontos tratados nesta introdução. Por todo o tex to se encontram exemplos de manifestações de riscos mais ou menos catastróficas, mostrando muitas vezes como é sentida a dimensão social das catástrofes - "a desigualdade face ao risco subsiste entre países ricos e países pobres e entre ricos e pobres no próprio seio dos diferentes países" (p. 15).

Seguem-se fichas em páginas duplas com "temas e documentos", de grande interesse pedagógico-didáctico. Alguns casos expostos são bem conhecidos, por terem sido espectaculares e, às vezes, relativamente recentes - inundações em Vargas (Venezuela), Limpopo (Moçambique), Dacca (Bangladesh), Oder (Polónia) e Aude (França), sismos em Kobe (Japão) e São Francisco (EUA), etc. Apesar de exemplo histórico, o terramoto de Lisboa do $1^{\circ}$ de Novembro de 1755 aparece com grande desenvolvimento (p. 60-61) verificando-se o cuidado enorme da Autora em localizar e explicar de modo simples toda a complexidade da catástrofe.

3.Climat.D'hierà demain, de Sylvie JOUSSAUME, é um livro de divulgação científica, muito cuidado, e que depois de uma primeira edição, premiada, em
1994, aparece em segunda edição nas CNRS Éditions (Paris, 1999), com uma apresentação muito agradável, bem ilustrado e bem fundamentado nas muitas questões que aborda ao longo das suas 143 páginas.

Não sendo um livro sobre riscos naturais, a verdade é que não foge deles. Logo na introdução, por exemplo, aflora as mudanças climáticas, em particular no respeitante a uma das suas manifestações mais violentas - a secura na Europa nos anos de 1989 e 1990. Mais adiante fala de ciclones tropicais e dos seus efeitos devastadores em termos de inundações. Também o fenómeno El Niño é apresentado com todas as consequências registadas em 1982-1983, tal como os efeitos "devastadores" da deflorestação em grande, por exemplo, em Madagascar. A perspectiva em que todos estes casos são apresentados é mais a do processo físico ("aléa"), do que do risco propriamente dito, incluindo a noção de vulnerabilidade. No entanto, a Autora, sempre que é caso disso, não deixa de insistir em perdas humanas.

\section{Referências bibliográficas}

DAUPHINÉ, André (2001) - Risques et Catastrophes, Observer Spatialiser-Comprendre-Gérer. Paris, Armand Colin, $288 \mathrm{p}$.

FAUGĖRES, Lucien (1990) - « La dimension des faits et la théorie du risque ». Le Risque et la Crise, Malta, Foundation for International Studies, p. 31-60.

JOUSSAUME, Sylvie (1999) - Climat. D'hier à demain. Paris, CNRS Éditions, $143 \mathrm{p}$.

REBELO, Fernando (1995) - "Os conceitos de risco, perigo e crise e a sua aplicação ao estudo dos grandes incêndios florestais". Biblos, Coimbra, 71, p. 511-527.

VEYRET-MEKDJAN, Yvette (2001) - Géographie des Risques Naturels. Paris, Documentation Photographique, n⿳0 8023, 63 p.

\section{Tese de doutoramento em Geografia Física sobre movimentos de vertente e SIG}

\section{Fernando Rebelo}

Movimentos de Vertente no NW de Portugal, Susceptibilidade Geomorfológica e Sistemas de Informação Geográfica é o título da tese de CARLOS VALDIR BATEIRA com que obteve o seu grau de doutor em Geografia Física pela Faculdade de Letras da Universidade do Porto, no passado mês de Janeiro de 2002. Na sua versão policopiada e ainda a única disponível, tem 475 páginas, com 31 fotografias e 75 figuras, entre as quais muitos mapas.
Dividida em quatro partes, tem, no total, 12 capítulos, sem contar com a "Introdução" e a "Conclusão". A primeira parte (Parte A) intitula-se "Os Sistemas de Informação Geográfica e a Cartografia dos Riscos Naturais" e tem três capítulos, mais sobre os SIG do que sobre os riscos...

A Parte B é a "Caracterização regional do NW de Portugal e da área experimental (Guimarães)". Tratando-se de um estudo sobre movimentos de 